\title{
A hybrid fuzzy MCDM approach for project selection problem
}

\author{
Kayvan Salehi*
}

Department of Industrial Engineering, Payam Noor University of Boukan, P. O. Box: 59516-79848, Boukan, Iran

\begin{tabular}{|c|c|}
\hline C H R O N I C L E & A B S T R A C T \\
\hline $\begin{array}{l}\text { Article history: } \\
\text { Received March 14, } 2014 \\
\text { Accepted August 10, } 2014 \\
\text { Available online } \\
\text { August } 122014 \\
\text { Keywords: } \\
\text { Project selection } \\
\text { AHP } \\
\text { VIKOR } \\
\text { Fuzzy theory }\end{array}$ & $\begin{array}{l}\text { Nowadays, selection of an optimal project has become a challenging task for managers and } \\
\text { decision makers. Project selection for a decision maker can be viewed as a complicated multi- } \\
\text { criteria decision making (MCDM) problem, which requires consideration of a number of } \\
\text { conflicting, tangible and intangible selection criteria. Moreover, decision makers tend to use } \\
\text { linguistic terms for expressing their assessments because of their different backgrounds and } \\
\text { preferences, some of which may be uncertain and incomplete. Hence, this paper focuses on } \\
\text { developing a hybrid fuzzy MCDM approach by combining AHP and VIKOR for solving the } \\
\text { project selection problem. Finally, A numerical example is proposed to illustrate an application } \\
\text { of the proposed method. }\end{array}$ \\
\hline
\end{tabular}

(C) 2015 Growing Science Ltd. All rights reserved.

\section{Introduction}

Project selection (PS) problem is one of the most important issues in managerial decision making. For project selection, the decision maker, or decision makers, has a large set of criteria for selecting projects, which are associated with intangible or conflicting attributes. The problem is to compare various criteria and to determine their relative importance through pairwise comparison. Hence, the project selection is a multi-criteria decision making (MCDM) problem. In addition to, in project selection models, the goals and parameters are generally assumed to be deterministic /crisp. However, real-world project selection problems are subject to many sources of imprecise/fuzzy owing to incomplete and unobtainable information. Therefore using fuzzy theory or probability theory can be a promising approach. There are various methods on project selection in the different fields. The majority of accomplished works often yield complicated mathematical programming such as mixedinteger or nonlinear programming (e.g. Weingarten, 1966a, b; Hall et al., 1992; Ansoff, 1970; Ignizio, 1976; Hawkins \& Adams, 1974; Badri et al. 2001; Yavuz \& Captain, 2002; Gabriel et al. 2006; Rabbani et al. 2006; Huang, 2007; Carlsson et al., 2007; Rabbani et al., 2010; Khalili-Damghani et al., 2012; Khalili-Damghani et al., 2013). 
However, in recent years, many multi criteria decision making (MCDM) methods have been developed for handling PS problems. Mohanty (1992) used The Technique for Order of Preference by Similarity to Ideal Solution (TOPSIS) approach, as an MCDM technique, for the project selection problem. Mohanty et al. (2005), in other work, proposed a fuzzy analytical network process (ANP)based approach to R\&D project selection. Enea and Piazza (2004) proposed a constrained fuzzy analytical hierarch process (AHP) method for the project selection problem. Mahmoodzadeh et al. (2007) applied fuzzy AHP and TOPSIS method for project selection. Amiri (2010) employed AHP and fuzzy TOPSIS methods for project selection in oil-field development. Daneshvar Rouyendegh and Erol (2012) presented a fuzzy ELECTRE method for selecting the best project using TOPSIS method. However, a number of studies have shown that VIKOR obtain better results against TOPSIS method (Chu et al., 2007; Opricovic \& Tzeng, 2004; Raei \& Jahromi, 2012). This paper presents a hybrid fuzzy approach of AHP and VIKOR techniques for solving project selection problem.

To achieve this purpose, the rest of this paper is organized as follows: In section 2, some notation about fuzzy sets and fuzzy numbers is explained. Section 3 discusses fuzzy hybrid AHP and VIKOR approach for solving project selection problem. In order to evaluate efficiency proposed algorithm, a numerical example is given in section 4. Finally, in Section 5, we draw conclusions and future researches.

\section{Fuzzy Set Theory}

Definition 2.1 Consider a Fuzzy set $\tilde{a}$ in a universe of discourse $X$ characterized by a membership function $\mu_{\tilde{a}}(x)$, which is associated with each element $x$ in $X$, a real number in the interval[0,1].

The function value $\mu_{\tilde{a}}(x)$ terms the grade membership of $x$ in $\tilde{a}[1]$. In this study, we use triangular fuzzy numbers defined by $\left(a_{1}, a_{2}, a_{3}\right)$. The mathematical form is as follows:

$\mu_{\tilde{a}}(x)=\left\{\begin{array}{lc}0 & x \leq a_{1} \\ \frac{x-a_{1}}{a_{2}-a_{1}} & a_{1}<x \leq a_{2} \\ \frac{a_{3}-x}{a_{3}-a_{2}} & a_{2}<x \leq a_{3} \\ 1 & x>a_{3}\end{array}\right.$

To calculate addition, multiplication and divided between two fuzzy numbers $\tilde{a}=\left(a_{1}, a_{2}, a_{3}\right)$, $\tilde{b}=\left(b_{1}, b_{2}, b_{3}\right)$ are as follows,

$$
\begin{aligned}
& \tilde{a}+\tilde{b}=\left(a_{1}+b_{1}, a_{2}+b_{2}, a_{3}+b_{3}\right) \\
& \tilde{a} * \tilde{b}=\left(a_{1} * b_{1}, a_{2} * b_{2}, a_{3} * b_{3}\right) \\
& \tilde{a} / \tilde{b}=\left(a_{1} / b_{3}, a_{2} / b_{2}, a_{3} / b_{1}\right)
\end{aligned}
$$

\section{The Fuzzy AHP and Fuzzy VIKOR Method}

\subsection{Fuzzy AHP}

The AHP method was originally developed by Saaty (1980) in order to determine the relative importance of a set of activities in a multi-criteria decision problem. This approach is essentially formulated for understanding the complex problem using a hierarchical structure. A hierarchy has at least three levels: the focus or overall goal of the problem at the top, multiple attributes (criteria) that define alternatives in the middle, and competing alternatives at the bottom (Saaty, 1980). AHP is frequently used to solve the multiple criteria decision-making problems and has successfully been applied in many practical contexts (Amiri, 2010). In spite of its popularity, this method is often 
criticized because it cannot handle the inherent uncertainty and imprecision which are associated with the mapping of DM's perceptions to exact numbers, traditional AHP requires exact or crisp numbers (Tiryaki \& Ahlatcioglu, 2009).

In conventional AHP (Saaty et al., 1980) for portfolio selection, the primary objective is to set up a hierarchy consisting of the final goal of the problem or the decision to be made, a number of criteria, the sub-criteria associated with each main criterion, and a number of alternatives to select. In conventional AHP, the uncertainty associated with the mapping of human judgment to a number of natural language does not take into account; the ranking of the AHP method is rather imprecise; and the subjective judgment of perception, evaluation, improvement and selection based on preference of decision-makers have great influence on the AHP results. To overcome these problems, we use fuzzy theory as a powerful tool for decision-making in an uncertain environment with AHP method. Fuzzy AHP method steps can be stated as follow (Lu et al., 2007):

Step 1: Determine the relative importance of the decision criteria. By a pairwise comparison, the matrix $\widetilde{D}$, containing fuzzy estimates for the relative significance of each pair of factors, is constructed. We use the linguistic variable in Table 1 for pairwise comparisons of criteria

$\widetilde{D}=\left[\begin{array}{ccc}\tilde{x}_{11} & \cdots & \tilde{x}_{1 n} \\ \vdots & \ddots & \vdots \\ \tilde{x}_{m 1} & \cdots & \tilde{x}_{m n}\end{array}\right]$

where $\tilde{x}_{i j}^{k} \forall i, j$ is linguistic variable, that can be described by a triangular fuzzy number, $\tilde{x}_{i j}^{k}=$ $\left(a_{i j}, b_{i j}, c_{i j}\right)$.

\section{Table 1}

The 1-9 fuzzy conversion scale

\begin{tabular}{llll}
\hline 1 & $(1,1,1)$ & 5 & $(4.0,5.0,6.0)$ \\
2 & $(1.6,2,2.4)$ & 7 & $(5.6,7,8.4)$ \\
3 & $(2.4,3,3.6)$ & 9 & $(7.2,9,10.8)$ \\
\hline
\end{tabular}

Step 2: Calculate fuzzy estimates for the weights or priorities of the decision criteria based on the matrix $\widetilde{D}$

$\left(\widetilde{w}_{1}, \widetilde{w}_{2}, \ldots, \widetilde{w}_{n}\right)$

where $\widetilde{w}_{j}, j=1,2, \ldots, n$ is a linguistic variable, that can be described by a triangular fuzzy number, $\widetilde{w}_{j}=\left(w_{j 1}, w_{j 2}, w_{j 3}\right)$. In this paper, a fuzzy pairwise comparison considered and the comparison matrix is normalized into the range of $[0,1]$ by

$\tilde{e}_{i j}=\frac{\tilde{x}_{i j}}{\sum_{i=1}^{m} x_{i j}}$

Now the weight of each criterion is computed by Eq. (8) as follows,

$\widetilde{w}_{i}=\frac{\tilde{e}_{i j}}{\sum_{j=1}^{n} \tilde{e}_{i j}}$

\subsection{Scoring alternatives}

After calculating the importance weights of criteria, a modified fuzzy VIKOR approach is applied for conducting the ranking process. Here, VIKOR is chosen because it is one of the most favorable MCDM techniques among researchers, and it has been successfully applied to various problems and contexts. The flow chart of the proposed approach is depicted in Fig 1. 


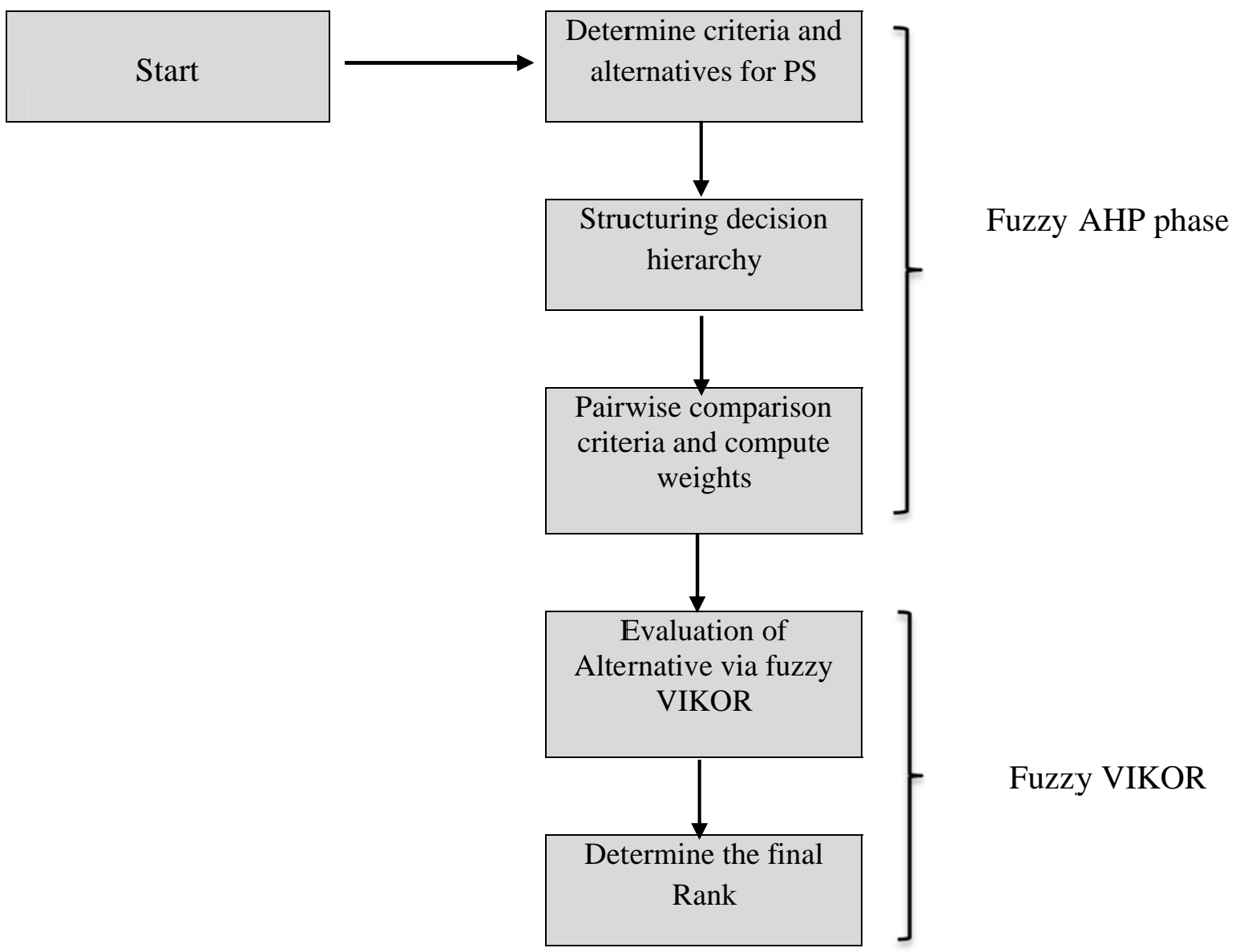

Fig. 1. Schematic diagram of the proposed model for project selection

\subsection{Fuzzy VIKOR}

The VIKOR method was first developed by Pricovic and Tzeng (2002, 2004) for solving multicriteria optimization problems. This method focuses on ranking and sellecting from a set of alternatives, and determines the compromise solution for a problem with conflicting criteria, which helps decision makers reach a final solution (Chu et al., 2007). The multi-criteria measure for compromise ranking is developed from the $L P$ - metric used as an aggregating function in a compromise programming method (Zeleny, 1982).

Assuming that each alternative is assessed based on each criterion; the compromise ranking can be performed by comparing the measure of closeness to the ideal alternative. The various $m$ alternatives are denoted as $A_{1}, A_{2}, A_{3}, \ldots ., A_{m}$. for alternative $A_{i}$, the rating of the $j$ th aspect is denoted by $f_{i j}$, i.e. $f_{i j}$ is value of $j$ th criterion function for the alternative $A_{i} ; n$ is the number of criteria. The fuzzy VIKOR method is briefly review as steps follows:

Step 1: Form matrix evaluation alternatives in term of criteria as follows:

$D=\left[\begin{array}{ccc}\tilde{x}_{11} & \cdots & \tilde{x}_{1 n} \\ \vdots & \ddots & \vdots \\ \tilde{x}_{m 1} & \cdots & \tilde{x}_{m n}\end{array}\right]$

where $\tilde{x}_{i j}$ is performance alternative $j ; j=1,2,3, \ldots, n$ in terms of criteria $i ; i=1,2,3, \ldots, m$.

Step 2: Construct the normalized fuzzy performance decision matrix as follows, 
$F=\left[\begin{array}{ccc}\tilde{f}_{11} & \cdots & \tilde{f}_{1 n} \\ \vdots & \ddots & \vdots \\ \tilde{f}_{m 1} & \cdots & \tilde{f}_{m n}\end{array}\right]$

where $\tilde{f}_{i j}=\frac{\tilde{x}_{i j}}{\sum_{j=1}^{m} \tilde{x}_{i j}} \quad \forall i=1,2,3, \ldots, m$

Step 3: Determine the fuzzy best value (FBV) and fuzzy worst value (FWV):

$\tilde{f}_{j}^{*}=\max \tilde{x}_{i j} \forall i$

$\tilde{f}_{j}^{-}=\min \tilde{x}_{i j} \forall i$

Step 4: Compute the values $\tilde{S}_{i}$ and $\tilde{R}_{i}$, by the following relationships

$\tilde{S}_{i}=\sum_{j=1}^{n} \frac{\widetilde{w}_{j}\left(\tilde{f}_{j}^{*}-\tilde{x}_{i j}\right)}{\left(\tilde{f}_{j}^{*}-\tilde{f}_{j}^{-}\right)}$
$\tilde{R}_{i}=\max \frac{\widetilde{w}_{j}\left(\tilde{f}_{j}^{*}-\tilde{x}_{i j}\right)}{\left(\tilde{f}_{j}^{*}-\tilde{f}_{j}^{-}\right)} \forall j=1,2, \ldots, n$.

where $\widetilde{w}_{j}$ are the weights of criteria, expressing their relative importance.

Step 5: Compute the index $\tilde{Q}_{i}$

$\tilde{Q}_{i}=\frac{v\left(\tilde{S}_{i}-\tilde{S}^{*}\right)}{\left(S^{-}-S^{*}\right)}+(1-v) \frac{v\left(\tilde{R}_{i}-\tilde{R}^{*}\right)}{\left(R^{-}-R^{*}\right)}$

where $\tilde{S}^{*}=\min \tilde{S}_{i}, \tilde{S}^{-}=\max \tilde{S}_{i}, \tilde{R}^{*}=\min \tilde{R}_{i}, \tilde{R}^{-}=\max \tilde{R}_{i}$.

Here, $v$ is introduced as the weight in strategy of the maximum group utility, namely $v=0.5$.

Step 6: Defuzzify fuzzy number $Q_{i}$ and rank the alternatives, sorting by the value $Q_{i}$. Consequently, the smaller the value $Q_{i}$, the better the alternative. In order to convert fuzzy number $Q_{i}$ into crisp values, in this paper, we employed Chen and Hseih’s (1999) approach as follows:

Let $\tilde{a}=\left(a_{1}, a_{2}, a_{3}\right)$ be a triangular fuzzy number. Crisp equivalent this fuzzy number based on Chen and Hseih (1999) is given in Eq (16).

$\operatorname{mean}(a)=\frac{\left(a_{1}+4 a_{2}+a_{3}\right)}{6}$

\section{Numerical example}

In order to illustrate the proposed approach, a case study is presented. After discussion with the expert team, four criteria were considered to evaluate the projects. These criteria include net present value (C1), quality (C2), contractor's technology (C3), and contractor's economic status (C4). Three projects, P1, P2 and P3 are assigned to be evaluated in this problem. Decision hierarchy structured with the determined alternative projects and the criteria are provided in Fig. 2. In the first step, using fuzzy AHP, four criteria are evaluated as shown in Table 2. 


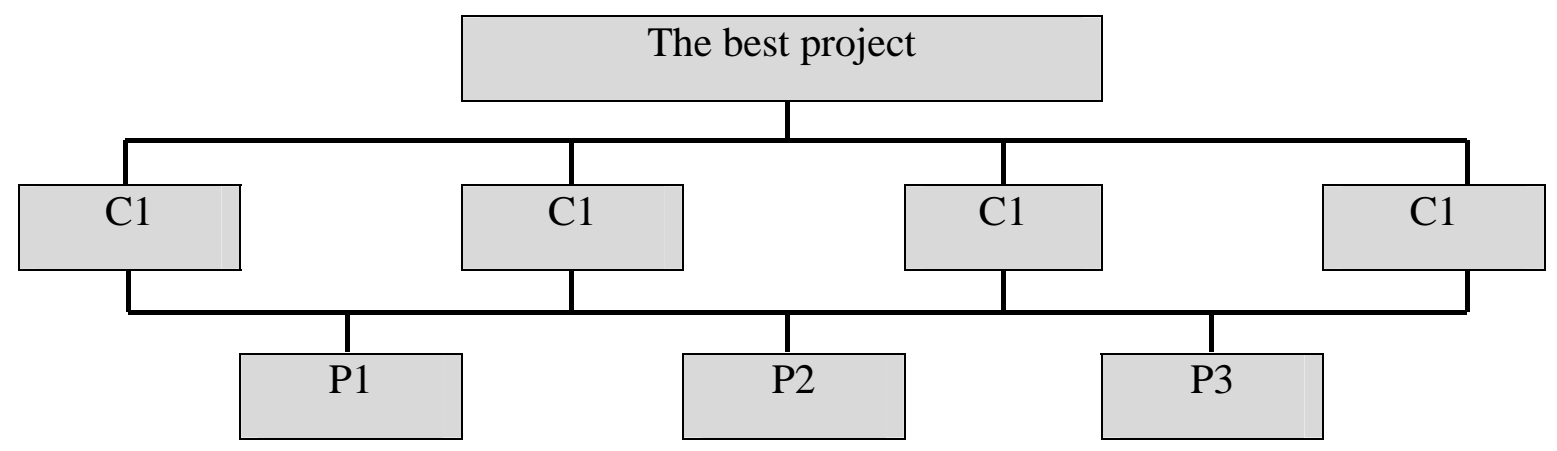

Table 2

Fig 2. Decision hierarchy structure

Matrix for criteria (pairwise comparison)

\begin{tabular}{ccccc}
\hline & $\mathrm{C} 1$ & $\mathrm{C} 2$ & $\mathrm{C} 3$ & $\mathrm{C} 4$ \\
\hline $\mathrm{C} 1$ & $(1,1,1)$ & $(2.4,3,3.6)$ & $(4,5,6)$ & $(1.6,2,2.4)$ \\
$\mathrm{C} 2$ & & $(1,1,1)$ & $(2.4,3,3.6)$ & $(2.4,3,3.6)$ \\
$\mathrm{C} 3$ & & $(1,1,1)$ & $(4,5,6)$ \\
$\mathrm{C} 4$ & & & & $(1,1,1)$ \\
\hline
\end{tabular}

The results obtained from the computations based on the pairwise comparison matrix provided in Table 2, are presented in Table 3.

Table 3

Results obtained with fuzzy AHP

\begin{tabular}{|c|c|c|c|}
\hline Criteria & weights & Criteria & weights \\
\hline C1 & $(0.34,0.46,0.63)$ & C3 & $(0.13,0.18,0.26)$ \\
\hline $\mathrm{C} 2$ & $(0.18,0.24,0.34)$ & $\mathrm{C} 4$ & $(0.08,0.11,0.15)$ \\
\hline
\end{tabular}

In Table 4, the fuzzy rating of three candidates to construct the triangular fuzzy number decision matrix is given. In next step the values $\tilde{f}_{j}^{*}$ and $\tilde{f}_{j}^{-}$are determined as Table 5.

Table 4

fuzzy decision matrix

\begin{tabular}{ccccc}
\hline & C1 & C2 & C3 & C4 \\
\hline P1 & $(4,5,6)$ & $(5.6,7,8.4)$ & $(2.4,3,3.6)$ & $(4,5,6)$ \\
P2 & $(5,6,7,8.4)$ & $(2.4,3,3.6)$ & $(4,5,6)$ & $(4,5,6)$ \\
P3 & $(4,5,6)$ & $(4,5,6)$ & $(2.4,3,3.6)$ & $(2.4,3,3.6)$ \\
\hline
\end{tabular}

\section{Table 5}

Fuzzy best value $\left(\tilde{f}_{j}^{*}\right)$ and fuzzy worst value $\left(\tilde{f}_{j}^{-}\right)$

\begin{tabular}{ccccc}
\hline & $\mathrm{C} 1$ & $\mathrm{C} 2$ & $\mathrm{C} 3$ & $\mathrm{C} 4$ \\
\hline$\tilde{\boldsymbol{f}}_{\boldsymbol{j}}^{*}$ & $(5.6,7,8.4)$ & $(5.6,7,8.4)$ & $(4,5,6)$ & $(4,5,6)$ \\
$\tilde{\boldsymbol{f}}_{\boldsymbol{j}}^{-}$ & $(4,5,6)$ & $(2.4,3,3.6)$ & $(2.4,3,3.6)$ & $(2.4,3,3.6)$ \\
\hline
\end{tabular}

As stated in above relationships, the index $\tilde{S}_{i}$ and $\tilde{R}_{i}$ are computed in Table 6. Applying relevant equations, the indexes of $S^{*}, S^{-}, R^{*}$ and $R^{-}$can be shown in Table 7.

\section{Table 6}

Index $\tilde{S}_{i}$ and $\tilde{R}_{i}$

\begin{tabular}{cccc}
\hline & C1 & C2 & C3 \\
\hline$\tilde{\boldsymbol{S}}_{\boldsymbol{i}}$ & $(-0.17,0.65,-3.35)$ & $(-0.26,0.24,-1.34)$ & $(-0.02,0.88,-2.50)$ \\
$\widetilde{\boldsymbol{R}}_{\boldsymbol{i}}$ & $(-0.10,0,-6.90)$ & $(0.07,0.24,1.30)$ & $(0.01,0.46,2.33)$ \\
\hline
\end{tabular}


Table 7

Index $S^{*}, S^{-}, R^{*}$ and $R^{-}$

$\begin{array}{lll}\boldsymbol{S}^{*}: & (-0.26,0.24,-3.35) & \boldsymbol{S}^{-}:(-0.26,0.24,-1.34) \\ \boldsymbol{R}^{*} & (-0.10,0,-6.90) & R^{-}:(0.07,0.46,2.33)\end{array}$

Based on above relationships, the $\tilde{Q}_{i}$ for each project is computed as Table 8 .

Table 8

Index $\tilde{Q}_{i}$

\begin{tabular}{cccc}
\hline & P1 & P2 & P3 \\
\hline$\widetilde{\boldsymbol{Q}}_{\boldsymbol{i}}$ & $(-0.08,0.32,-0.95)$ & $(-0.001,0.26,-0.06)$ & $(-0.12,1,-0.16)$ \\
\hline
\end{tabular}

Finally, the triangular fuzzy number $\tilde{Q}_{i}$ is defuzzified into a crisp number $Q_{i}$ as Table 9 .

\section{Table 9}

Index $\widetilde{Q}_{i}$ and rank for projects

\begin{tabular}{cccc}
\hline & P1 & P2 & P3 \\
\hline$\widetilde{\boldsymbol{Q}}_{\boldsymbol{i}}$ & 0.04 & 0.16 & 0.62 \\
Rank & 1 & 2 & 3 \\
\hline
\end{tabular}

\section{Conclusions}

In this work, an integrated MCDM approach was proposed for project selection problem. Integrated approach has consisted of AHP and VIKOR techniques. Fuzzy set theory has been applied for two techniques in order to make the evaluation process more prices and more flexible for the decision makers. Usage of fuzzy set in describing uncertainties in different factors simplified the complex structure of the decision phase. The proposed hybrid structure for project selection is the unique feature of the present study, which has not been reported in the literature. The future researches can be focused on two issues: First employing the proposed approach for other fields in management and industrial engineering. Second various kinds of MCDM methods can be hired in future studies regarding project selection.

\section{References}

Amiri, M. P. (2010). Project selection for oil-fields development by using the AHP and fuzzy TOPSIS methods. Expert Systems with Applications, 37(9), 6218-6224.

Ansoff, H. I. (1970). Corporate strategy: An analytic approach to business policy for growth and expansion. Penguin books.

Badri, M. A., Davis, D., \& Davis, D. (2001). A comprehensive 0-1 goal programming model for project selection. International Journal of Project Management, 19(4), 243-252.

Carlsson, C., Fullér, R., Heikkilä, M., \& Majlender, P. (2007). A fuzzy approach to R\&D project portfolio selection. International Journal of Approximate Reasoning, 44(2), 93-105.

Chen, S. H., \& Hsieh, C. H. (1999). Graded mean integration representation of generalized fuzzy number. Journal of Chinese Fuzzy Systems, 5(2), 1-7.

Chu, M. T., Shyu, J., Tzeng, G. H., \& Khosla, R. (2007). Comparison among three analytical methods for knowledge communities group-decision analysis. Expert Systems with Applications, 33(4), 1011-1024.

Daneshvar Rouyendegh, B., \& Erol, S. (2012). Selecting the best project using the Fuzzy ELECTRE Method. Mathematical Problems in Engineering, 2012.

Enea, M., \& Piazza, T. (2004). Project selection by constrained fuzzy AHP. Fuzzy Optimization and Decision Making, 3(1), 39-62.

Fréville, A. (2004). The multidimensional 0-1 knapsack problem: An overview. European Journal of Operational Research, 155(1), 1-21. 
Gabriel, S. A., Kumar, S., Ordonez, J., \& Nasserian, A. (2006). A multiobjective optimization model for project selection with probabilistic considerations. Socio-Economic Planning Sciences, 40(4), 297-313.

Hall, N. G., Hershey, J. C., Kessler, L. G., \& Stotts, R. C. (1992). A model for making project funding decisions at the National Cancer Institute. Operations Research, 40(6), 1040-1052.

Hawkins, C. A., \& Adams, R. A. (1974). A goal programming model for capital budgeting. Financial Management, 52-57.

Huang, X. (2007). Optimal project selection with random fuzzy parameters. International journal of production economics, 106(2), 513-522.

Ignizio, J. P. (1976). An approach to the capital budgeting problem with multiple objectives. The Engineering Economist, 21(4), 259-272.

Lorie, J. H., \& Savage, L. J. (1955). Three problems in rationing capital. The Journal of Business, 28(4), 229-239.

Lu, J., Zhang, G., \& Ruan, D. (2007). Multi-objective group decision making: methods, software and applications with fuzzy set techniques. Imperial College Press.

Mahmoodzadeh, S., Shahrabi, J., Pariazar, M., \& Zaeri, M. S. (2007). Project selection by using fuzzy AHP and TOPSIS technique. World Academy of Science, Engineering and Technology, 30, 333-338.

Medaglia, A. L., Graves, S. B., \& Ringuest, J. L. (2007). A multiobjective evolutionary approach for linearly constrained project selection under uncertainty. European Journal of Operational Research, 179(3), 869-894.

Mohanty, R. P. (1992). Project selection by a multiple-criteria decision-making method: an example from a developing country. International Journal of Project Management, 10(1), 31-38.

Mohanty, R. P., Agarwal, R., Choudhury, A. K., \& Tiwari, M. K. (2005). A fuzzy ANP-based approach to R\&D project selection: a case study. International Journal of Production Research, 43(24), 5199-5216.

Opricovic, S., \& Tzeng, G. H. (2002). Multicriteria planning of post-earthquake sustainable reconstruction. Computer-Aided Civil and Infrastructure Engineering, 17(3), 211-220.

Opricovic, S., \& Tzeng, G. H. (2004). Compromise solution by MCDM methods: A comparative analysis of VIKOR and TOPSIS. European Journal of Operational Research, 156(2), 445-455.

Rabbani, M., Aramoon Bajestani, M., \& Baharian Khoshkhou, G. (2010). A multi-objective particle swarm optimization for project selection problem. Expert Systems with Applications, 37(1), 315321.

Rabbani, M., Tavakkoli-Moghaddam, R., Jolai Ghazvini, F., \& Ghorbani, H. R. (2006). A Comprehensive Model for $\mathrm{R}$ and D Project Portfolio Selection with Zero-One Linear GoalProgramming (RESEARCH NOTE). International Journal of Engineering-Transactions A: Basics, 19(1), 55.

Raei, R., \& Jahromi, M. (2012). Portfolio optimization using a hybrid of fuzzy ANP, VIKOR and TOPSIS. Management Science Letters, 2(7), 2473-2484.

Saaty, T. L., Rogers, P. C., \& Pell, R. (1980). Portfolio selection through hierarchies. The Journal of Portfolio Management, 6(3), 16-21.

Satty, T. L. (1980). The Analytic hierarchy Process.

Tiryaki, F., \& Ahlatcioglu, B. (2009). Fuzzy portfolio selection using fuzzy analytic hierarchy process. Information Sciences, 179(1), 53-69.

Weingartner, H. M. (1966). Capital budgeting of interrelated projects: survey and synthesis. Management Science, 12(7), 485-516.

Weingartner, H. M. (1966). Criteria for programming investment project selection. The Journal of Industrial Economics, 65-76.

Yavuz, S., \& Captain, T. A. (2002). Making project selection decisions: a multi-period capital budgeting problem. International Journal of Industrial Engineering, 9(3), 301-310.

Zeleny, M. (1982). Multiple criteria decision making (Vol. 25). J. L. Cochrane (Ed.). New York: McGraw-Hill. 